\title{
LA PARRHESIA DE ISIDORO DE PELUSIO O CUANDO POLITEIA Y PAIDEIA LLEGAN A ENCONTRARSE
}

\author{
Antonia Vento \\ Departamento de Ciencias de la Antigüedad, "Escuela de doctorado" en Ciencias \\ Arqueológicas e Históricas ciclo XXIVFecha de recepción: 6-III-2011 \\ Universidad de Messina \\ E-mail: antonia.vento@tin.it
}

Fecha de recepción: 6-III-2011

Fecha de aceptación: 12-IV-2011

Resumen: Un estilo de vida riguroso (politeia) - lo que corresponde a un monje - y una educación retórica (paideia) - lo que corresponde a un sophistes - son las dos virtudes que reúne Isidoro, monje del desierto de Pelusio. Él es portavoz de una philosophia monastike que apunta a varias direcciones: al perfeccionamiento moral de cada hombre renunciando a lo material (apotaghe) y profundizando en el estudio de la Sagrada Escritura; al perfeccionamiento de sus hermanos monjes, que se puede alcanzar con la obediencia a una regla; a la mejora de la sociedad cristiana y laica, poniendo en práctica la parrhesia. Isidoro, si bien se ha retirado en el desierto, no ha abdicado de su dimensión social y actúa, previas solicitudes explícitas, ayudando a los pecadores a retomar el camino de la rectitud, censurando a los klerikoi inobservantes y a los archontes corruptos, invitándoles a cumplir correctamente con sus obligaciones, o denunciándoles si reinciden, reconfortando a los afligidos e interesándose en muchos aspectos de la vida social: asistencia a los pobres, educación de los jóvenes.

Palabras Clave: Antigüedad Tardía, Isidoro de Pelusio, monaquismo, libertad de palabra, arche

ABSTRACT: A severe life style (politeia) - proper of a monk - and rhetorical education (paideia) - proper of a sophist - are both gifts that Isidor, monk from the desert, possesses. He is the spokesman of a philosophia monastike oriented towards several directions: his own and his brothers' moral improvement, through a break with the materiality (apotaghe) and an in-depth study of the Scriptures; his own and his brothers' devotional submission to a rule; improving both Christian and laic societies, through the exercise of the parrhesia. Though retired in the desert, Isidor never abdicates his social dimension and he strongly commits himself, by explicit request, in order to conduct the sinners to the straight and narrow path. He reproaches the defaulting klerikoi, the corrupted archontes, by asking them 
to perform their duty honestly, or by denouncing recidivism. He consoles the afflicted and he is interested in various aspects of social life: assistance to the poor, education of the young.

Key Words: Late Antiquity, Isidor from Pelusio, monasticism, parrhesia, arche

\section{INTRODUCCIÓN}

El tema general de este encuentro invita a reflexionar sobre la dialéctica entre razón, utopía y sociedad, por tanto sobre la aspiración del hombre entendida como uno de los impulsos fundamentales y permanentes de su ser - a vivir en una sociedad ideal, una vez sanadas las incongruencias y las injusticias del vivir diario. Ésta ha cuajado históricamente en la razón aplicada a la construcción política y en la fe religiosa. En el periodo tardoantiguo, el orgullo pragmático del civis, la paideia helenístico-romana y el cristianismo asimilan toda aspiración utópica y la encauzan, mediante la labor de figuras concretas de obispos y monjes ${ }^{1}$, hacia el bien de la comunidad. Éste es el venero que alimenta la presente ponencia con la que se pretende dirigir la atención sobre las ideas, las herramientas comunicativas y la extremada voluntad de una figura de monje que pese a no ser única, no deja de ser interesante. Hablamos de Isidoro de Pelusio, activo en Egipto entre finales del siglo IV y comienzos del V d.C. En una época compleja, tan llena de cambios, presagio de nuevos periodos como la Antigüedad Tardía, este religioso realizó con notable empeño y lucidez un esfuerzo muy significativo para mejorar la condición de sus referentes y de la realidad de la ciudad donde vivían, con la fuerza del ejemplo moral y de su cultura.

Isidoro amonestaba al emperador Teodosio ${ }^{2}$ sobre asuntos de política religiosa y fiscal, así como a otros personajes del poder (praepositi sacri cubiculi, prefectos del pretorio, gobernadores de la provincia) al objeto de que reflexionaran sobre algunas cuestiones. Por este motivo y desde un punto de vista prosopográfico, estrictamente histórico, ampliamente cultural, sus cartas son una mina de información pues nos permiten conocer nombres de notables que de lo contrario permanecerían desconocidos; denuncian malversaciones, invitan al uso correcto del poder, a distintos niveles de la escala jerárquica laica y eclesiástica, se ocupan de los problemas de la educación de los jóvenes, reflexionan sobre el correcto mestizaje entre cultura pagana y nueva filosofía cristiana y sobre la conducta adecuada de

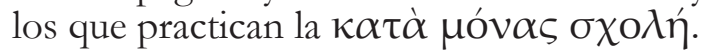

1 C. Neri, Parrhesia ed imperium. Scontro tra due poteri derivanti da Dio nel mondo tardoantico en Tyrannis, Basileia, Imperium. Forme, prassi e simboli del potere politico nel mondo greco e romano. Giornate seminariali in onore di S. Nerina Consolo Langher, Discam, Messina 2010, págs. 527-535.

2 I, 31 y 311. 
Hasta hace relativamente poco, nada se había percibido acerca del interés histórico del epistolario isidoriano3 ${ }^{3}$ En un ensayo de 1993 Peter Brown considera a Isidoro como el heredero de los logoi, el sistema cultural que las élites griegas construyeron a lo largo de los siglos con un increíble esfuerzo simbólico. Instrumento del filósofo en un principio y herramienta del monje después, estos logoi son el significante de una paideia que no hay que entender stricto sensu como cultura personal sino en un sentido más amplio, como patrimonio colectivo irrenunciable que en el relevo entre paganismo y cristianismo reciben como testigo determinadas figuras carismáticas ${ }^{4}$, entre las que se encuentra Isidoro. El emperador, que ya no es pagano sino cristiano, símbolo en la tierra de Dios-emperador celeste, ahora cede ante el monje en lugar de ante el filósofo, precisamente para demostrar a sus súbditos que por ser hombre, comparte con ellos una humanidad común y afligida. De hecho en la Antigüedad Tardía el propio lenguaje del poder asumió un tono nuevo porque lo hablaban los cristianos. Éstas son las palabras de Brown en ese mismo ensayo del 93. «L'emergere del monaco quale eroe alternativo al filosofo tradì con eccezionale chiarezza uno spostamento decisivo nel lento orbitare della società urbana tardoclassica, dove filosofi e vescovi si erano mossi contemporaneamente. Il monaco riassunse nella sua personalità le potenzialità di una cultura e soprattutto di un modello di società che resero irrevocabile la fine del mondo pagano-classico» ${ }^{5}$. Isidoro es uno de los artífices de este cambio y su epistolario es instrumento y testimonio de ello. «Quel che ci è rimasto delle sue lettere riempie ottocento colonne della Patrologia Graeca. Isidoro scriveva per porgere il benvenuto e insieme le sue istruzioni ai governatori. Redarguiva il suo proprio vescovo e i suoi intimi. Ammaestrava gli intellettuali su ogni e qualsiasi argomento, dalla virtù della povertà alla condotta delle donne, ai miracoli di Apollonio di Tyana - la cui vita asseriva di aver letto attentamente - al fatto che Noè avesse mangiato insalata nell'Arca. [...] Isidoro viveva con un piede piantato nel deserto e l'altro fermamente piantato nella sua città. Con un uomo di penna così aguzza, che aveva un'opinione su ogni cosa e ognuno, non vi era un gran bisogno di rivolgersi a un filosofo pagano» ${ }^{6}$

3 P. Brown, Il filosofo e il monaco: due scelte tardoantiche, en Storia di Roma 3, L'età tardoantica, Turín 1993; P. Évieux, Lettres 1214-1413, París 1995; íd, Isidore de Péluse, París 1997; íd, Lettres, 1414-1700, París 2000.

4 P. Brown, Power and persuasion in Late Antiquity, Madison 1992. Véase también C. Neri, La società degli asceti nelle Conlationes di Giovanni Cassiano en «Studi e Materiali di Storia delle Religioni», 21, 1997, págs. 37-42. La connotación cultural y social de los monjes descritos por Casiano es la de una élite presentada como modelo carismático y representativa de una nueva clase dirigente.

5 Brown, Il filosofo e il monaco, cit., pág. 878.

6 Íd, ibíd., págs. 891-892. 
Los ideales cristianos, monásticos y sociales impregnan las páginas del corpus isidoriano y a menudo chocan con una realidad distinta a la realidad perseguida con tanta obstinación y lucidez mediante la fuerza de la palabra.

Isidoro coteja las verdaderas cualidades del filósofo pagano con las del filósofo cristiano: libertad de palabra y vida rigurosa para el primero, estilo de vida acorde con la verdadera doctrina para el segundo 7 . Isidoro demuestra que posee todas estas virtudes, él es por tanto un monje-filósofo, consciente hacedor de una síntesis entre dos experiencias culturales contiguas y co-presentes capaces de descifrar cuál es el fin al que ajustarse para vivir una vida cristiana pero también de saber cómo vivir la vida en el mundo. Él señala las herramientas esenciales para llevar una vida merecedora del cielo, condición previa irrenunciable para una correcta comprensión de las Escrituras y garantía de vida eterna ${ }^{8}$ : amor por la sabiduría y especial atención a los dogmas. Hay que cultivar la virtud, que es un bien inmortal y no el éxito o la prosperidad económica, que son bienes fugaces ${ }^{9}$. La forma correcta de vivir la vida terrenal es ser consciente en todo momento de lo que es eterno y de lo que no lo es. Y si a todos los cristianos se les invita a llevar una vida de santidad, no hay duda de que a los clérigos se les exige un compromiso mayor, por vivir en el mundo, y por tanto, por estar expuestos a las miradas y a los juicios de los demás ya que representan unas responsabilidades determinadas ${ }^{10}$; pero aún mayor si cabe es el compromiso que se les pide a los monjes que han renunciado de forma radical a lo terrenal y aspiran a superar la condición humana, anticipando en la tierra el reino de Dios. Así, en una carta dirigida a Sereno, Isidoro dice que, aunque hayan sido expulsados del

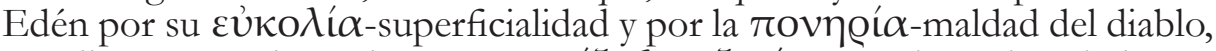
aquellos que se alejen de una $\chi \alpha \mu \alpha i \zeta \eta \lambda$ os $\zeta \omega \eta$, una existencia guiada por

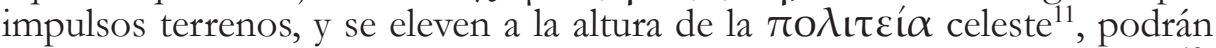
regresar a ese lugar de beatitud. Pero en otro texto es aún más explícito ${ }^{12}$, pues recuerda que la philosophia ${ }^{13}$ tiene el deber de mantener a distancia el ruido y que la vida monástica es posible sólo en lugares lejos del bullicio, geográficamente aislados, donde es posible alcanzar una condición mental libre de toda ocupación o discurso inoportuno. No hay que creer que

$7 \mathrm{IV}, 34$.

$8 \mathrm{IV}, 33$.

$9 \mathrm{~V}, 527$.

10 Cfr. Syn., ep., CV.

11 I, 282.

12 I, 92.

13 Para la polivalencia de este término, véase A. M. Malingrey, Philosophia. Étude d'un groupe de mots dans la littérature grecque des présocratiques au IVe siècle ap. J. C., París 1961. 
para vivir una vida de ángel es suficiente con tener una capa, unas barbas largas y un bastón. No se puede estar en medio de la muchedumbre o ver espectáculos llenos de imágenes y sonidos en la ciudad. Para olvidar nuestra animalidad, hay que tener la capacidad de provocar conflictos de orden moral en nuestro interior, luchar contra nuestra conciencia y mantener una conducta sobria. Para ayudar a sus hermanos en esta difícil tarea, Isidoro da también consejos prácticos: por lo que se refiere a la comida, no hay que ayunar, porque se corre el riesgo de debilitarse físicamente pero tampoco hay que exagerar, porque comer demasiado provoca entorpecimiento y por consiguiente daños en el alma y en el cuerpo ${ }^{14}$. El equilibrio correcto reside en una alimentación moderada que se limita a lo que es necesario para el organismo. Según Isidoro el vino no le conviene a un monje que goza de buena salud ${ }^{15}$. En cuanto a la indumentaria, los monjes simplemente tienen que cubrir su desnudez. Con la $\mu \eta \lambda \omega ́ \tau \eta$, una piel de carnero, es suficiente. En general, la idea di Isidoro para una vida ascética, es que hay que tener mesura y humildad ${ }^{16}$, el exceso es dañino. La virtud es oú $\mu \mu \varepsilon \tau \varrho \varsigma^{17}$ por naturaleza y su búsqueda es un bien porque conlleva una participación activa

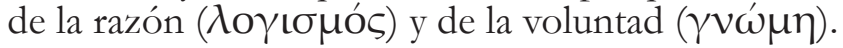

\section{LA RETÓRICA AL SERVICIO DEL MENSAJE}

Para conseguir su ideal de perfectibilidad, Isidoro recurre a menudo a un lenguaje metafórico, pero no con fines retóricos sino para que su interlocutor lo utilice como un instrumento para entenderle. Utiliza las metáforas para ofrecer un referente concreto para conceptos que de lo contrario podrían resultar enredosos o podrían seguir siendo de alguna manera abstractos. Y así dice que la vida pecaminosa es como una tormenta que alborota la mar y aleja de la orilla que es Jesucristo ${ }^{18}$; que el deber de un buen monje es superar el obstáculo de las corrientes, el embate de los vientos y llegar a la tranquilidad del puerto $^{19}$; el hombre que no deja que nada perturbe su alma es comparado a un piloto que en medio de la tormenta sabe mantener firme el timón; en cambio el que deja que su barco se hunda es aquel que se deja arrastrar por las pasiones, por lo que los $\pi \alpha ́ \alpha \eta$ prevalecen sobre la

14 I, 424. Cass., Conl., II, 24 recuerda a un monje que en la mesa era muy inconstante y que acabó huyendo del desierto

15 I, 385. Para el uso del vino en ambiente monástico véase Apophth. Patr., n. 148 y Pall., HL, VII, 4.

$16 \mathrm{I}, 468$.

17 II, 45; 979, V, 328.

$18 \mathrm{I}, 115$.

19 I, 91. 


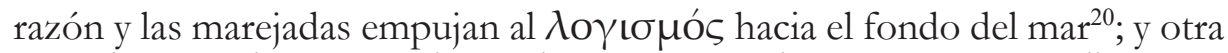
vez a los pecadores conscientes los compara a los perros que se alimentan de su propio vómito o a los cerdos que se revuelcan en su propio barro ${ }^{21}$. Son muchas las reflexiones sobre el uso de la palabra. En una carta dirigida al monje Casiano ${ }^{22}$, Isidoro declara que se alegra de que el joven se haya retirado a la vida monástica, sin embargo no oculta su preocupación por la presunción de su lengua ${ }^{23}$. Si un hombre no sabe frenar la $\gamma \lambda \tilde{\omega} \tau \tau \alpha$ es como si construyera una muralla alta e inaccesible para defenderse de los enemigos pero dejándoles abierta la puerta de entrada. Más allá de la metáfora, el hablar de forma soberbia y ofensiva es señal de vulnerabilidad y para un monje es síntoma de ambigüedad, de falta de coherencia entre lo que refleja al exterior y su condición interior. En otro momento Isidoro reitera la importancia de la $\gamma \lambda \tilde{\omega} \tau \tau \alpha$, por ejemplo cuando afirma que el discurso que quiere suprimir el vicio debe ser pronunciado por una lengua $\varepsilon u ̋ \phi \eta \mu o \varsigma$ y $\sigma \varepsilon \mu \nu \eta^{24}$, de lo contrario aquel que lo pronuncia corre el riesgo de ensuciarse con la culpa;

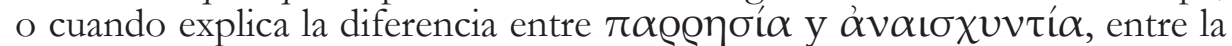
libertad de palabra y el descaro: la primera reprocha oportunamente a los que yierran y la segunda ultraja a los que actúan correctamente, además la primera es un medicamento que cura a los enfermos y la segunda es una peste que destruye a los que están sanos ${ }^{25}$. Hay una relación de reciprocidad entre vida, mente y forma de hablar: sólo la uniformidad entre pensamiento, palabra y acción puede garantizar la transparencia en las relaciones con los demás. De hecho es una condición básica para que haya amistad verdadera ${ }^{26}$ entre los hombres y con Dios.

\section{LA PARRHESIA ISIDORIANA}

Isidoro, pues, exhorta, ofrece unos patrones para una vida donde rigen los principios cristianos. Pero el auténtico interés del corpus isidoriano acaso resida en su fuerte componente de denuncia. Recordemos que la $\pi \alpha @ \varrho \eta \sigma i ́ \alpha$ junto con la $\pi 0 \lambda \iota \tau \varepsilon$ ć $\alpha$ es para él una herramienta imprescindible del filósofo cristiano. No teme mencionar los casos de irregularidad en la administración periférica de la Iglesia y del Estado que él ve con sus propios ojos o de

$20 \mathrm{~V}, 88$.

21 I, 92.

22 I, 309.

23 Gr. Nac., or. XXVI, PL 36, col. 292 aconseja a los que tienen una $\gamma \lambda \tilde{\omega} \sigma \sigma \alpha \pi \varrho 0 \pi \varepsilon \tau \tilde{\eta} \varsigma$, que sean juiciosos.

$24 \mathrm{~V}, 453$.

25 V, 417. Cfr. Syn., regn., 2

26 III, 43; V, 560. 
los que tiene constancia porque le informan sus interlocutores. Lietta De Salvo afirma en un ensayo dedicado a nuestro monje: «In campo civile, due cose preoccupano principalmente Isidoro: la corruzione dei governatori e l'eccessiva pressione fiscale che da quella deriva, e riduce in miseria molti piccoli coltivatori, costringendoli o ad entrare al servizio dei grandi proprietari terrieri o ad andare nel deserto a ingrossare le file dei monaci $\rangle^{27}$. Es el caso de las denuncias contra Ghigantios, ex corrector de Augustamnica, que pretende conseguir un segundo mandato. Mediante unas cartas, Isidoro se dirige a conciudadanos y a funcionarios de estado para impedir una segunda

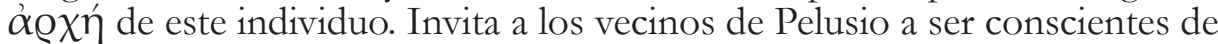
la situación real y a no dejarse llevar por las promesas sino más bien a pensar concienzudamente en el bien de la patria y a no repetir los errores del pasado y evitar sufrir daños de los que ya tienen experiencia suficiente. Ruega a los funcionarios que impidan que Ghigantios ocupe una vez más el cargo. Los delitos de este mal gobernador son las falsas acusaciones lanzadas contra

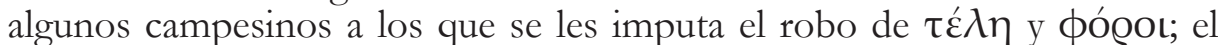
aumento de impuestos - ya de por sí onerosos para los contribuyentes - y la creación de uno nuevo, así como el tramar contra las uniones matrimoniales y la violación de tumbas. Acusaciones similares se pueden encontrar también en textos de distintos autores de la Antigüedad Tardía, y como ocurre con algunos otros como Sinesio y Teodoreto, el testimonio isidoriano es muy útil y nos permite realizar un estudio prosopográfico de notables que de lo contrario seguirían siendo desconocidos. Nos ofrece además noticias sobre la vida de una ciudad muy activa como Pelusio, noticias respaldadas por las campañas de excavación de Tell El-Farama que han sacado a la luz restos de la época tardoantigua.

\section{DEONTOLOGÍA DEL PODER: BASILEUS Y GOBERNADORES}

El valor añadido del corpus epistolar es la extremada voluntad de Isidoro. Él no sólo se limita a denunciar sino que también propone el modelo del buen funcionario. Contra la práctica consolidada del poder, que a menudo obedece a intereses particulares, él propone una deontología del ejercicio del poder. La instancia educativa y formativa es una constante en su voluntad comunicativa. Él busca siempre un ideal para darle forma en la tierra como un propedéutico de la perfección de la condición celeste. Aquellos que denuncian necesitan el modelo positivo porque arroja luz sobre los fallos del modelo vigente y ofrece un punto de apoyo para crecer moralmente. $\mathrm{Al}$ praefectus Augustalis Teodoro ${ }^{28}$, Isidoro le dice que el detentor de un poder, aunque posea riqueza, felicidad y fuerza, puede ser alabado y se le puede considerar feliz sólo en el caso de que no se deje dominar por un soberbio

27 L. De Salvo, Aspetti sociali nell'epistolario di Isidoro di Pelusio, «Koinonia», 28-29, 2004-2005, págs.169-180, pág. 172.

28 III, 50. 


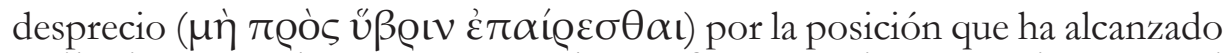
y sólo si es capaz de pensar en pasado y en futuro. La riqueza no tiene porqué

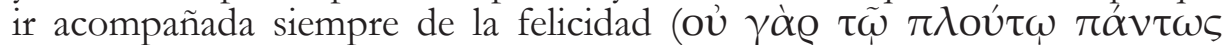

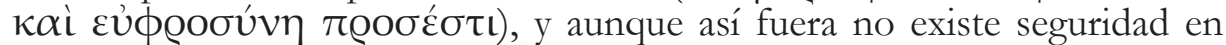

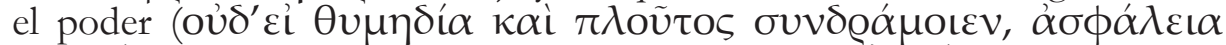
$\pi \varrho 0 \sigma \varepsilon ́ \sigma \tau \alpha \mathbf{l})$. Sin embargo cuando se posee una $\alpha \varrho \chi \eta ́$, cualquiera que sea su nivel de poder, siempre hay que tener en cuenta unos principios. Para que perdure, un poder debe ir है'vvouos, acorde con la ley, y debe ejercerse según unas modalidades determinadas. Para poder mandar sobre los demás, el soberano debe actuar con arreglo a la ley (útò $\tau \tilde{\omega} v$ vó $\mu \omega v$

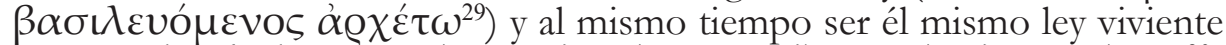

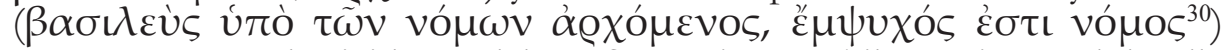
«per stemperare la rigidezza del ius fisso e immutabile, aggiornandolo alle nuove esigenze dei tempi, in nome dei valori dell'umanità e dell'equitàı ${ }^{31}$. En primer lugar la actitud del que manda ${ }^{32}$ debe ser de generosidad ( $\tau$ ò

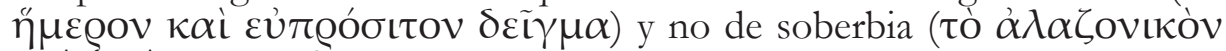

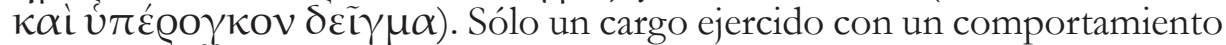
filantrópico $^{33}$ es verdadero ejercicio del poder porque resulta muy útil

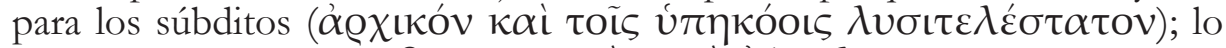

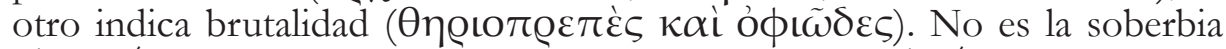

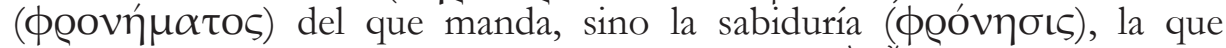

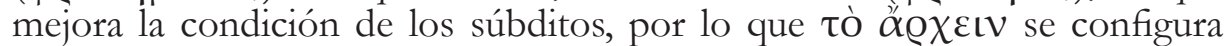
como seguro ( $\left.\alpha \sigma \phi \alpha \lambda \varepsilon^{\prime} \varsigma\right)$, y no tambaleante ( $\left.\sigma \phi \alpha \lambda \varepsilon \varrho o ́ v\right)$, tanto para el que

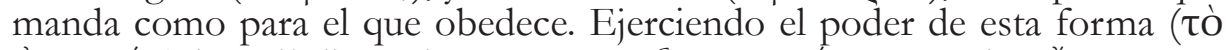

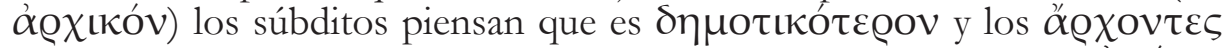
por su parte ganan un respeto que es más poderoso que el temor ( $\dot{\alpha} \gamma \alpha \dot{\alpha} \pi \eta$

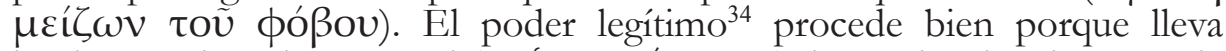

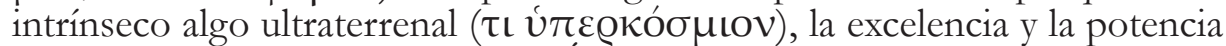

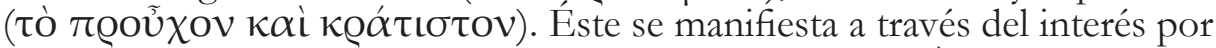

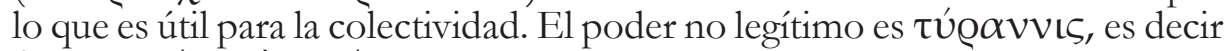

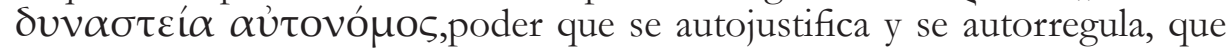

29 V, 225. Aquí Isidoro insiste en la necesidad de que el soberano no rehuya la ley: Eỉ toù

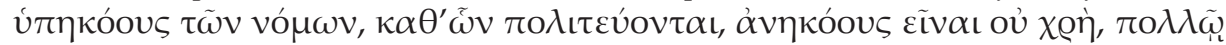

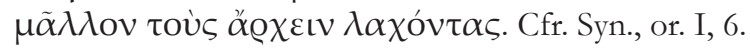

30 III, 306. Cfr. Tem., or. XIX, 2.

31 L. De Giovanni, Il 'Problema giustizia' nel tardoantico en G. Bonamente-R. Lizzi, Istituzioni, carismi ed esercizio del potere (IV-VI secolo d. C.), Munera 31, Bari 2010, págs. 171-181, pág. 177.

$32 \mathrm{~V}, 372$.

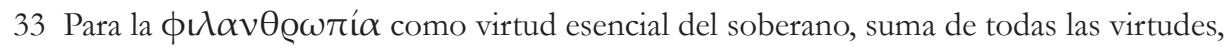
cfr., por ejemplo, Tem., or. I, 8.

$34 \mathrm{IV}, 143$. 
no recibe su autoridad del $\chi \alpha ́ \varrho \iota \sigma \mu \alpha$ divino y que por tanto se mueve hacia lo útil personal de quien lo ejerce ${ }^{35}$. Éste es un poder que indica brutalidad

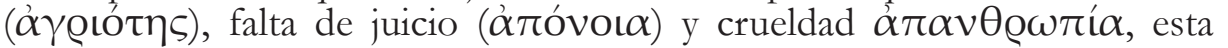
última, concebida como negación de la virtud que en el basilikos logos es condición previa para el ejercicio de la basileia, es un disvalor y un rasgo del poder tiránico. En cambio la devoción $\left(\varepsilon \dot{v} \sigma \varepsilon \dot{\beta} \beta \varepsilon \alpha^{36}\right)$ es la corona de los

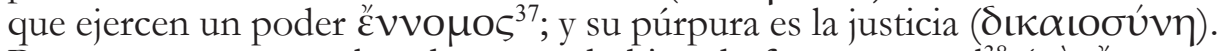

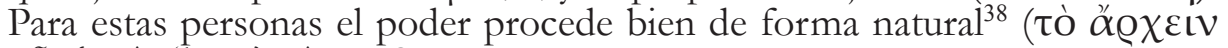

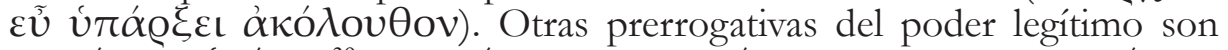

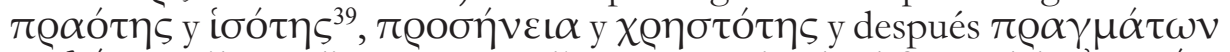
$\gamma \alpha \lambda \eta ́ v \eta$. Sólo mediante estos atributos se enciende el fuego del cuvvouí $\alpha$. El hogar de un buen gobierno es la justicia ${ }^{40}$.

El corpus isidoriano, además, nos ilustra con ejemplos de funcionarios correctos que son elogiados por Isidoro. Por ejemplo, en ocasión de la elección de Simplicio ${ }^{41}$, no oculta su alegría y su profundo aprecio por su

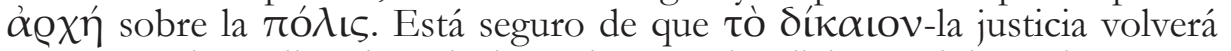
a recorrer las calles de Pelusio y de que Simplicio tendrá a Dios como

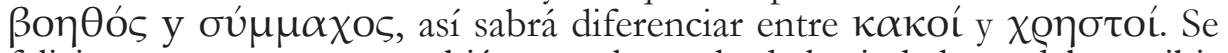
felicita por este evento también con el senado de la ciudad que debe recibir su elección con serenidad y confiar en el sabio propósito de su voluntad

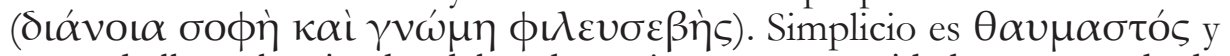
capaz de llevar las riendas del poder y ejerce una autoridad que procede de

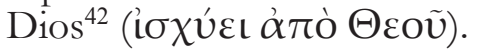

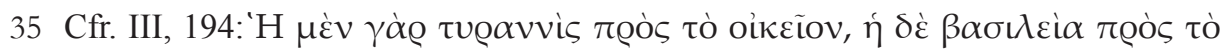

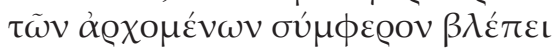

36 Para el significado que Isidoro atribuye al término, véase III, 163.

37 Cfr. Syn., or. I, 10.

38 La concesión divina en Eusebio de Cesarea era la garantía de un largo reinado. Cfr. S. Calderone, Teologia politica, successione dinastica e consecratio in età costantiniana en Le culte des souverains dans l'empire romain, Ginebra 1973, págs. 213-269; Íd., Eusebio e l'ideologia imperiale en Le trasformazioni della cultura nella tarda antichità. Atti del convegno tenuto a Catania, 27 sett.-2 ott. 1982, Roma, 1985, págs. 1-26; Íd., Il pensiero politico di Eusebio di Cesarea en G. Bonamente-A. Nestori (recopiladores), I cristiani e l'impero nel IV secolo. Colloquio sul cristianesimo nel mondo antico. Atti del convegno (Macerata 17-18 dicembre 1987), Macerata 1988, págs. 45-54.

39 I, 208.

40 I, 208.

41 I, 225 y 226.

42 Sobre la idea de poder y autoridad concedidas por Dios cfr. I, 484 y en particular II,

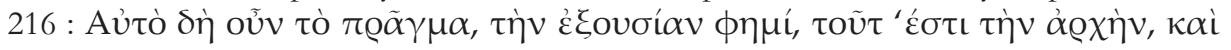

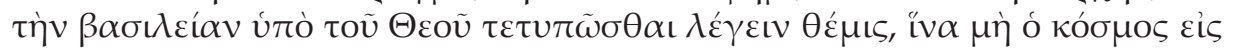




\section{El JUEZ SEGÚN ISIDORO}

En cuanto a la doble función administrativa y judicial de los gobernadores provinciales, Isidoro reflexiona a menudo sobre la complejidad

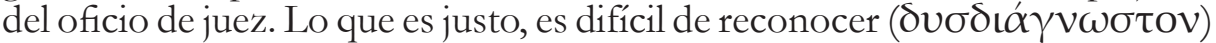
y de juzgar. Por eso el que juzga, el k@ıтńs, en primer lugar tiene que

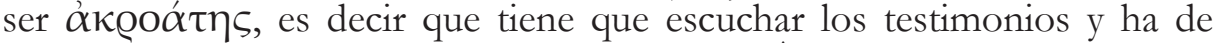

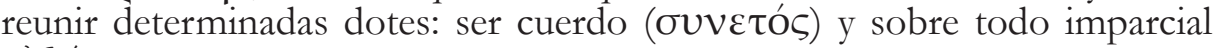

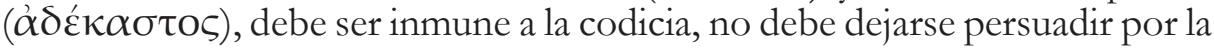
elocuencia de los testigos o de los imputados, ni por el poder de persuasión

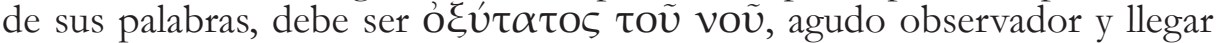
hasta lo más profundo del pensamiento. En sus cartas, donde reflexiona sobre la complejidad del oficio de juez, recurre a menudo a la metáfora de la

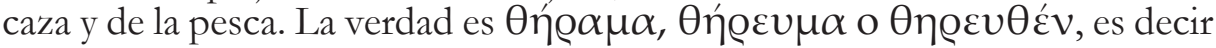
aquello que requiere habilidad para ser buscado, localizado y finalmente cazado. Lamentablemente el juez es a menudo $\beta \mathrm{o} \alpha \delta u ́ s$, lento en razonar; otras veces, aunque su ingenio es muy sutil, se deja seducir por el dinero y hace una compraventa de sentencias, o es parcial por varios motivos: por miedo, por adulación, por amistad, o por hostilidad hacia alguien. Al obispo Zósimo, que tuvo que ejercer de juez, en el marco de la episcopalis audientia ${ }^{43}$, por lo general se le acusa de poner a la venta su juicio. En un pasaje concreto del documento se especifica incluso con cierto desdén que su precio se cuantifica en unos pocos pescados. A Eusebio, otro obispo, le definen como $\theta \varrho \varepsilon ́ \mu \mu \alpha \alpha \dot{\alpha} \lambda \sigma \gamma\{\dot{\alpha} \alpha \varsigma$, hijo de la irracionalidad y no contaminado por ningún

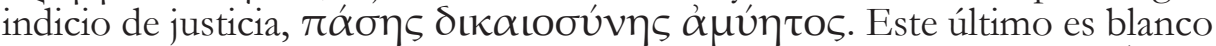
frecuente de las acusaciones de Isidoro. Se denuncia su $\delta \omega \varrho 0 \lambda \eta \psi i ́ \alpha$ en las ordenaciones sacerdotales, su olvido por las categorías de $\pi \varepsilon ́ v \eta \tau \varepsilon \varsigma$ y $\pi \tau \omega \chi \chi$ oí de las que se ocupa la Iglesia. En la epístola 127 del I libro, Isidoro denuncia a Cirilo, metropolita de Alejandría, la situación en la que vierte la iglesia de Pelusio por la mala gestión del obispo Eusebio. La acusación que Isidoro expone con toda claridad a Cirilo es la connivencia de Eusebio con su ecónomo. Los estropicios ocasionados por este individuo, con el beneplácito del obispo o incluso auspiciados por éste, han conducido a la población a una situación difícil y la iglesia a este punto es ultrajada convirtiéndose en objeto de burla por parte de quien debería administrarla en el nombre de Dios $^{44}$. Martiniano, cuyos orígenes no se conocen con exactitud, consiguió

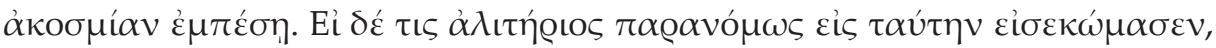

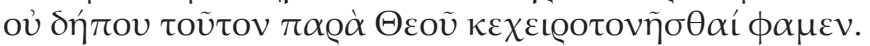

43 G. CrifÓ, A proposito di episcopalis audientia in M. Chistol, S. Demougin, Y. Duval (éd.), Institutions, société et vie politique dans l'empire romain au IV siècle ap. J.-C. Aactes de la table ronde autour de l'œuvré d'André Chastagnol (Paris, $20-21$ janvier 1989), Roma 1992, págs. 397-410.

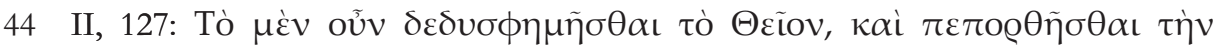

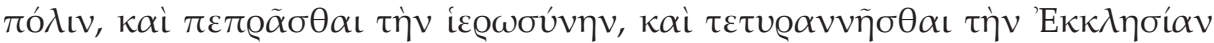


ser sacerdote de la iglesia de Pelusio, gracias a Eusebio ${ }^{45}$, y después se hizo ecónomo, es decir colaborador del obispo, encargado de la administración y de la gestión de los ingresos y de los gastos de la Iglesia, tenedor de los libros contables ${ }^{46}$. Martiniano roba dinero de las cajas, falsifica los libros contables para que la Iglesia resulte llena de deudas y el obispo suscribe estas acciones ilícitas. De esta forma los dos malhechores, en lugar de vigilarse mutuamente para garantizar la correcta gestión económica de los $\dot{\varepsilon} \kappa \kappa \lambda \varepsilon \sigma \iota \alpha \sigma \tau \iota \kappa \dot{\alpha} \chi \varrho \eta \mu \alpha \tau \alpha$, lo que consiguen es perjudicar sobre todo a los pobres, al haber roto ese engranaje de la economía caritativa que garantiza la iglesia por iniciativa estatal. Isidoro dice que estos dos hombres no tenian consideración alguna hacia los pobres, que saquearon los bienes de la Iglesia centrando sus esfuerzos en la búsqueda de beneficios personales ${ }^{47}$. Isidoro le pide a Cirilo que tome medidas para evitar las ocasiones en que se pueda incurrir en actividades ilegales: Martiniano debe ser excomulgado por un consejo de obispos sabios y hábiles ${ }^{48}$; Eusebio debe ser destituido o contar con la

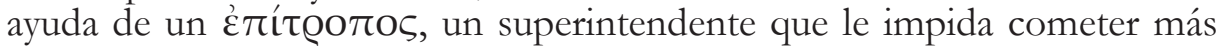
iniquidades ${ }^{49}$. Sin embargo la lucidez de la solución de Isidoro, exemplum de un modus operandi que se propone como finalidad de una sociedad sin duda mejor que la real, no es suficiente para que se cumpla el propósito deseado. La denuncia detallada y las propuestas concretas como toda solución, no bastaron para corregir de forma definitiva esta desagradable situación.

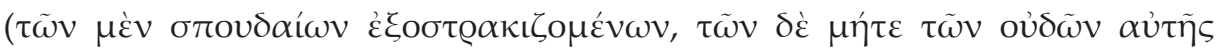

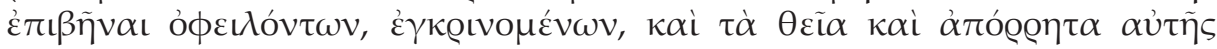

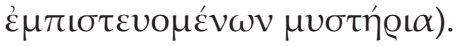

45 El obispo predecesor de Eusebio, Ausonio, hombre noble, lleno de sabiduría recibida como don por Dios, capaz de leer con sus ojos inquisitivos en el alma de Martiniano, no había aceptado su oferta.

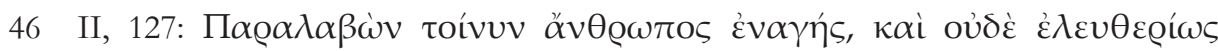

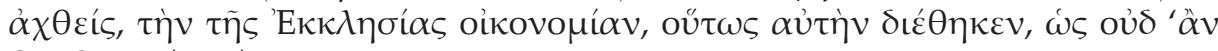

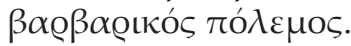

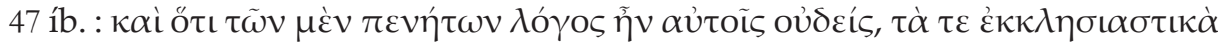

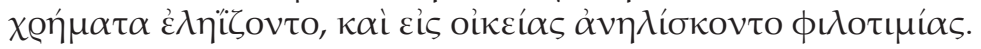

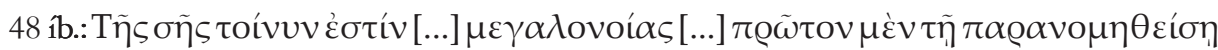

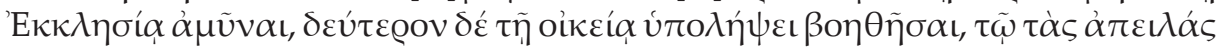

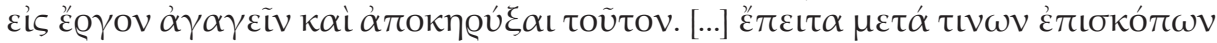

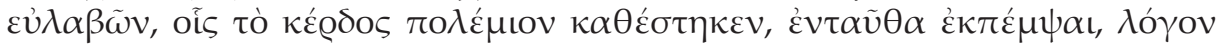

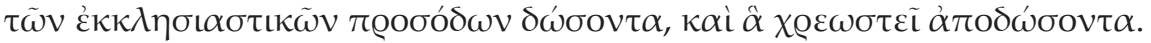

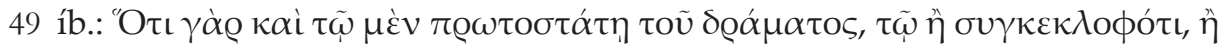

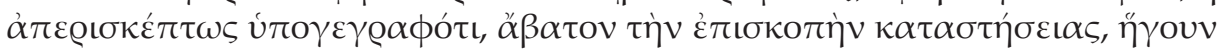

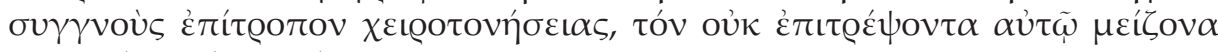

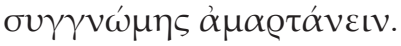


Las fuentes ${ }^{50}$ nos informan de que en el año 457, 22 años después de la muerte de Isidoro, Eusebio seguía siendo obispo de la ciudad. Por tanto cabe deducir que a pesar de la denuncia del monje, el obispo no había sido destituido. Sin embargo nos gustaría pensar que por lo menos el ecónomo fue excomulgado y expulsado, pero no disponemos de información sobre este punto.

A partir de aquí es interesante destacar que Isidoro actúa recurriendo a su gran capacidad de raciocinio y que sabe diferenciar las situaciones. No le da miedo denunciar o criticar, pero no tolera que otras personas, a las que quiere, se expongan personalmente. Por el intercambio epistolar con Harpócrates, ex discípulo de Isidoro, ahora sofista de la ciudad, sabemos que para denunciar a algunos de sus detractores, en vez de seguir un camino judicial, Isidoro prefiere utilizar sus grandes dotes: la retórica y la ironía. Contra ellos compuso una monodia con las características de un $\theta$ ̣ñvos, donde se mofaba de la muerte espiritual de estos maleantes. Isidoro aconseja no hacer pública esta composición ${ }^{51}$. Esos hombres son animales ( $\theta \eta @ i ́ \alpha$

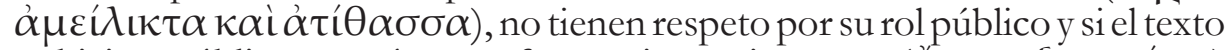

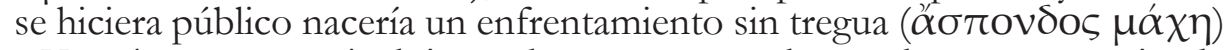
y Harpócrates correría el riesgo de pagar personalmente las consecuencias de las culpas de otros. Isidoro es muy consciente del riesgo que entraña el tener que tratar con personajes sin escrúpulos y la administración de la justicia en manos del corrector no era transparente como debería haber sido en la ciudad.

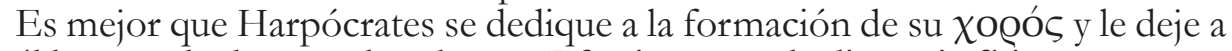
él la tarea de destapar los abusos. Efectivamente la distancia física respecto a la ciudad y la distancia espiritual respecto a las cosas del mundo garantizaban al monje una autonomía de juicio y una libertad de palabra.

\section{LA FORMACIÓN DE LOS JÓVENES Y LA PAIDEIA CRISTIANA}

El conflicto entre utopía y realidad en Isidoro se manifiesta también mediante su acción para fomentar un paradigma educativo entendido no genéricamente sino pragmáticamente, pensado para la primera etapa de formación de la futura cúpula del sophistes. El propio Isidoro educó a un

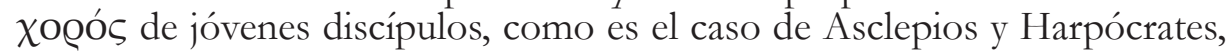
que en el corpus figuran entre sus destinatarios como profesionales de la cultura, elegidos por la curia de la ciudad y encargados de la educación de los jóvenes deseosos de hacer carrera en las oficinas del estado. La propuesta de Isidoro en el campo de la educación, trasciende los conocimientos escolares, los de la literatura griega y de las técnicas retóricas, y apunta hacia un ideal de perfección desde una perspectiva cristiana, de hecho, en su rol carismático

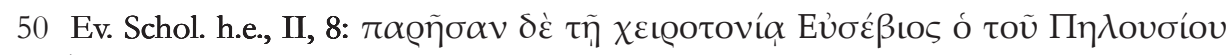

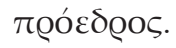

$51 \mathrm{~V}, 52$. 
de filósofo cristiano que se dedica a la interpretación de las Escrituras, la verdad del cristianismo seguramente goza de una posición más elevada con respecto a la formación pagana. Lamentablemente la retórica que se enseña en la escuela tiene sus limitaciones: apunta exclusivamente a la belleza y a la

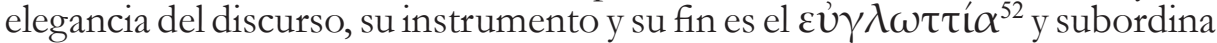
la profundidad del pensamiento a la forma. Su esencia es efímera, porque la belleza de la expresión es vana, su propósito no es modificar los comportamientos del que escucha ${ }^{53}$. La retórica es legítima sólo si está al servicio de la verdad y del bien; cuando ejerce una forma de violencia a la verdad - y esto ocurre a menudo - se vuelve culpable ${ }^{54}$. En cualquier caso la retórica es insuficiente: a pesar de que reúne todos los artificios y seduce a los oídos y a la mente, no acaba de penetrar en el corazón. Los que escuchan están dotados de libre albedrío y son ellos los que deciden ser persuadidos ${ }^{55}$, y a menudo, lo que seduce al oído, ni produce un cambio en el corazón ni tiene una aplicación práctica en los hechos. La retórica se queda en la superficie de las cosas, es una herramienta que utiliza un $\tau \varepsilon \chi v i ́ \tau \eta\rceil$ pero que no alcanza un resultado seguro y definido. Sin embargo la verdadera filosofía abarca todo el ser humano y su horizonte mental. En el discurso de Isidoro a Alfio ${ }^{56}$ - donde hace hincapié en el interés de su época por la retórica, instrumento que no mejora al auditorio sino que lo fascina y lo seduce - hay unas afirmaciones muy interesantes. En este discurso, a la retórica se la define como arte que no tiene nada de espiritual ni de apostólico sino que es sofístico y demosténico, incapaz de persuadir los ánimos y hábil sólo en seducir a los oídos. ¿Qué hacer entonces? ¿Se evita el uso de la palabra? ¡Rotundamente no! El que tenga el don de la elocuencia que lo utilice; ya se encargará el oyente, dotado de libre albedrío, de juzgar si sus afirmaciones son oportunas y darles un valor. Isidoro discrepa. El haberse apartado de la función pública de educador y de sophistes, a menudo encargado de pronunciar discursos para la curia, supuso la renuncia a la palabra como instrumento vano. El cese de la actividad anterior y la total dedicación, como monje, a la belleza y a la útil sencillez del evangelio, le permiten sustituir las múltiples ambigüedades de la retórica por el carácter unitario de palabra y vida. La retórica que él ha adquirido como arte se torna instrumental para la exégesis de la palabra de Dios según el ejemplo de Giovanni Crisostomo y de los padres Capadocios. El lenguaje que se ocupa de persuadir hacia el bien y la virtud y de interpretar los textos sagrados, ante todo debe ser conciso y claro

52 II, 42 ensalza la euglottia de Giovanni Crisostomo y su estilo refinado a través de las palabras de Libanio.

53 IV, 174.

$54 \mathrm{IV}, 215$ y V, 97.

$55 \mathrm{~V}, 442$ y 547.

56 V, 201. 


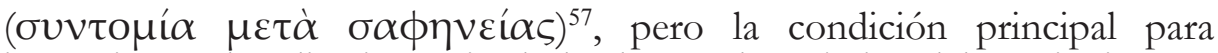
impresionar al auditorio es sin duda el ejemplo práctico del que invita con las palabras. Una vez aclarado que Isidoro rechaza la retórica profana, éste pone su habilidad técnica al servicio de la verdad y del bien y lo propone como modelo para los demás. Las afirmaciones de intransigencia hacia la cultura pagana son muy pocas pero perentorias. El elemento que hay que condenar sin ninguna duda es el aspecto espectacular de las formas con las que se manifiesta en la Antigüedad Tardía ${ }^{58}$ : representaciones mímicas, pantomímicas y carreras de carros. En las formas estrictamente teatrales, según la perspectiva cristiana, a la amoralidad de los contenidos se sumaba la depravación de los actores, a los que se les consideraba capaces de corromper al público con su propia forma de ser además de con su arte, calificada de $\kappa \alpha \kappa o \tau \varepsilon \chi v i ́ \alpha$. La femineidad de los bailarines era un factor que condicionaba a los jóvenes igual que la aptitud por los perjurios de los mimos, que por exigencias del guión estaban obligados a hacerlo en el escenario ${ }^{59}$. Acostumbrarse a reírse de comportamientos no risibles y dejarse llevar por la euforia en las carreras de caballos, apartan a los jóvenes de una actitud correcta en las relaciones interpersonales. Precisamente porque el espíritu de los jóvenes es susceptible de un proceso de formación y porque su carácter se plasma con facilidad; la risa y el desasosiego - reacciones del que el escenario y el hipódromo son un caldo de cultivo - encuentran fácilmente un lugar en sus espíritus. Por otro lado, la fascinación que sienten los jóvenes cuando ven algo agradable es realmente peligrosa para sus almas ingenuas. En Isidoro pues, igual que en otros autores cristianos, se percibe con fuerza la obsesión de la mirada y se manifiesta una forma de ensañamiento hacia aquellos vicios donde los ojos son la entrada del alma, como los que genera cualquier forma de espectacularidad, ya sea teatral o circense. Sólo alejando a los jóvenes de la seducción de la vista que con su placer atrapa sin remedio los espíritus todavía inmaduros, es posible formar a hombres honestos y a oradores de extraordinaria habilidad. En un impulso utópico, al final de una larga carta dirigida a Harpócrates ${ }^{60}$, Isidoro sueña con ciudades sin teatros o ciudadanos que prefieren evitar estos lugares e incluso cerrarlos; se imagina además los beneficios que la sociedad civil obtendría gracias a esta condición. Los beneficios son tres y de suma importancia: salvación para las almas, estabilidad para los organismos de la ciudad y seguridad para los gobernantes. Más en general, en la definición de la relación entre cultura

57 III, 57.

58 A. Vento, Gli spettacoli nella corrispondenza di Isidoro di Pelusio, «Koinonia», 34, 2010, págs. 181-193.

59 Tampoco Libanio (or., 26, 17-18; 39, 3 y 11,9) toleraba que sus estudiantes tuvieran tratos con pantomimos y mimos porque les distraían de sus estudios y sobre todo perjudicaban la reputación de su maestro.

$60 \mathrm{~V}, 185$. 
pagana y cultura cristiana, a pesar de que el juicio negativo sobre la mitología griega y sobre algunos poetas y escritores griegos es muy claro ${ }^{61}$, Isidoro afirma que hay algo bueno también en los paganos y que hay que hacer lo mismo que la abeja cuando succiona las flores ${ }^{62}$. Sobre todo las especulaciones de los filósofos respecto a la virtud ${ }^{63}$, sus hipótesis respecto a la existencia de un mundo más allá de la muerte ${ }^{64}$, la inmortalidad del alma ${ }^{65}$; o los modelos historiográficos de virtudes como Diógenes, Arístides, Epaminondas y Sócrates son unas manifestaciones imperfectas de una filosofía que encuentra su perfección en las nuevas especulaciones cristianas. Por tanto en lugar de insistir en los aspectos opuestos, hay que ensalzar los puntos de convergencia entre las Escrituras y la cultura griega ${ }^{66}$. La elocuencia debe convertirse en instrumento de la sabiduría divina y esto será posible si se crea una relación de subordinación de la $\varepsilon \hat{\gamma} \gamma \lambda \omega \tau \tau$ tí $\alpha$ a la $\sigma o \phi i ́ \alpha$, como la que hay entre el cuerpo y el alma o entre el instrumento y el músico. Si se rompe este orden y la $\tau \dot{\varepsilon} \chi \vee \eta$ quiere mandar en lugar de servir, entonces será posible prescindir de ella ${ }^{67}$. En algunas cartas Isidoro habla de la necesidad de una doble formación, cristiana y pagana, cuando afirma que hay que fundir la cultura viva con la cultura muerta ${ }^{68}$, llenar el vacío de la $\varepsilon \lambda \lambda \varepsilon v \iota \kappa \eta ்$

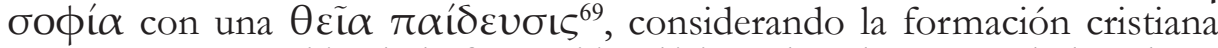
como una superación de la formación clásica y los elementos de la cultura anterior no como un mal que hay que suprimir sino como un elemento propedéutico a la nueva y más completa doctrina ${ }^{70}$. Bajo esta perspectiva es cómo hay que leer el intercambio epistolar con Asclepios y Harpócrates, que son sofistas, sí, pero cristianos, y en el ejercicio diario de su magisterio también dudaban sobre la rectitud de sus enseñanzas, especialmente en lo que se refiere a temas controvertidos de orden filosófico, como la existencia del destino o a asuntos más concretos como la pasión de las élites paganas y no por juegos y espectáculos.

La fe del monje y su autoridad, que no es otra cosa que su propio

$61 \mathrm{I}, 63$

62 II, 3

63 III, 61

64 III, 37; 154; 413; y IV, 125.

65 II, 256

66 II, 3; V, 281

$67 \mathrm{~V}, 281$.

$68 \mathrm{I}, 396$.

$69 \mathrm{IV}, 6$.

$70 \mathrm{IV}, 134$ 


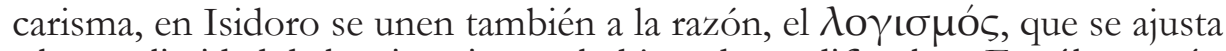
a la peculiaridad de las situaciones al objeto de modificarlas. ¿Es sólo utopía, esperanza cristiana de reproducir en la tierra la perfección del reino de los cielos? ¿ $\mathrm{O}$ es más bien un ejemplo de la fusión que se ha producido

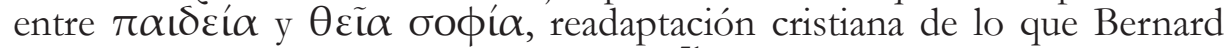
Schouler define como 'Tercera Sofística" ${ }^{71}$ ? Los logoi, instrumento pagano por excelencia de relación con el poder, adquieren una fuerza nueva si son utilizados por un monje que recibe su exousia directamente de Dios y que, al igual que Isidoro, la encauza respondiendo a exigencias concretas de personas reales, hacia la definición de un paradigma de perfectibilidad social.

71 En un discurso dictado en la sesión inaugural del Simposio Internacional en su honor (Libanios, le premier humaniste. Éducation, pensée politique, culture et rhétorique chez un auteur du IV siècle après Jésus-Christ, Montpellier 18-20 de marzo de 2010), Bernard Schouleur puso de relieve el interés de Libanio por el patrimonio cultural clásico concebido como herencia del pasado y herramienta de acción en el presente; la paideia libaniana, sustanciada por las virtudes codificadas en los esquemas filosóficos, phronesis, andreia, sophrosyne, dikaiosyne, y además por megalopsychia, philotimia, philoponia y philanthropia está al servicio de la comunidad bajo forma de parrhesia, libertad de palabra y valor político, privilegio de la educación y no de la riqueza y él la define como «terza Sofistica» de corte civil y vocación social. 